\title{
Communication at the International Workplaces: The Foreign Managers' Perspective
}

\author{
Adrian Wee Tiong Weng ${ }^{1}$ \\ ${ }^{1}$ Southern Cross University, Australia \\ Correspondence: Adrian Wee Tiong Weng, RMIT University Vietnam, Vietnam. E-mail: \\ adrian.wee@rmit.edu.vn \\ Received: February 3, 2014 \\ Accepted: February 25, 2015 \\ Online Published: March 27, 2015 \\ doi:10.5539/ijbm.v10n4p82 \\ URL: http://dx.doi.org/10.5539/ijbm.v10n4p82
}

\begin{abstract}
In the last decade Vietnam experienced rapid economic growth. The fast growing economy in turn attracted large numbers of international companies and their managers to set up shop on its shores. This paper reviews the relevant literature and draws from interviews with experienced international managers in Ho Chi Minh City or HCMC to identify the issues they faced when communicating with the local employees at work. This paper highlights the importance of knowing and understanding the different perspectives on communication.
\end{abstract}

Keywords: culture, communication, workplace, exploratory, qualitative, Vietnam

\section{Introduction}

\subsection{Background to the Study}

Vietnam has been described as a country undergoing change (Nguyen \& Robinson, 2010). The changes have been particularly pronounced in its economy. In 1986, after years of disappointing economic growth and runaway inflation, the socialist government embarked on 'doi moi' or economic reform. The primary aim of 'doi moi' was to stimulate economic activity by reforming state owned enterprises, encouraging small privately owned businesses and attracting foreign direct investments (Rowley \& Truong, 2009). Until recently 'Doi Moi' achieved tremendous success. Gross domestic product or GDP growth in Vietnam, averaged more than 7\% a year from 1995 to 2011. This was only slightly lower than China's average growth of $10 \%$ (World Bank, 2013). More recently inflationary pressures and weak demand from the global economic crisis dented Vietnam's economy to produce lackluster growth averaging $5 \%$ a year. Nonetheless, Vietnam's economy remain robust and economic growth is expected to rebound to more than $7 \%$ a year from 2015 as the world economy and the world demand for goods recovers (EIU, 2013).

\subsection{Significance of the Study}

The rapid growth in Vietnams' economy in turn brought in many international companies of repute. These companies which were in such short supply just over a decade ago now ply their trade alongside domestically grown state and privately owned enterprises. These companies however did not only bring in international practices but also international managers. Due to a combination of factors including the lack of skilled and qualified personnel, many of these companies introduced expatriate managers to work with the local employees.

Following in the heels of the international companies and their managers is the call for more industry ready graduates. Many of the companies apparently found it difficult to find local employees that match their needs. Complaints were made that the local employees lacked requisite skills and required additional training and expenses to bring them up to speed (Rowley \& Truong, 2009). Correspondingly, the World Bank $(2012,2013)$ noted a considerable shortfall in the supply of skilled labor and warned of its potential to negatively impact on Vietnam's economic future growth. Montague (2013) similarly observed that Vietnam, like many other newly emerging countries suffers from too many general workers and too little skilled labor.

The employees' purported lack of skills encompasses both the technical and behavioral including interpersonal communication skills (World Bank, 2012 \& 2013). With respect to communication, various writers noted the local employees' ability or rather inability to interact and communicate with the foreign managers a key issue (Scott \& Banon, 2008; Trung \& Swierczek, 2009). Similarly the World Bank report on Higher Education in East Asia, citing studies done by the local government agency MOLISA, surmised that communication and language 
remains one of the primary concerns for foreign managers operating in Vietnam (World Bank, 2012).

\subsection{Objective of This Study}

The purpose of this paper is to explore the concerns that the foreign managers have when communicating with their employees at work in HCMC, Vietnam. The aim is to explore in depth the communication concerns or communication issues at work from the foreign managers' perspective. Further, the issues raised would be examined from the perspective of culture and communication at work. Intuitively the managers and their employees come from different backgrounds and training and would think and behave differently. The plan of this paper is as follows.

In the first section, this paper will briefly review the literature on culture and communication. In the second section, the sample managers interviewed and the methodology used will be explained. The results of the sample study are displayed in the third section. In the fourth section we will discuss the results and recommend actions that the foreign managers can implement to facilitate workplace communication.

\section{Literature Review}

\subsection{What is Culture?}

Culture has been described as values and beliefs that a group of people share (Samovar, Porter, \& McDaniel 2009; Lustig \& Koester, 2010). Each cultural group would have a set of values that would determine for them what is right and wrong or good and bad (Hofstede, 2001). Between 1967 and 1973, Hofstede interviewed IBM employees working in more than 50 countries (Hofstede, 1980). Based on these interviews, Hofstede identified four value dimensions that set cultures apart, namely individualism-collectivism, power distance, uncertainty avoidance and masculinity-femininity.

Power distance generally refers to the distribution of power (Hofstede, 1980). Cultures can view hierarchy quite differently. Whilst high power distance cultures observe hierarchy, low power distance cultures advocate egalitarian practices. Uncertainty avoidance on the other hand refers to accepted levels of ambiguity or uncertainty (Hofstede, 1980). High uncertainty avoidance cultures are generally wary of uncertainties and risks. Low uncertainty avoidance cultures on the other hand embrace uncertainties as challenges to overcome.

Masculinity in turn refers to the emphasis placed on masculine values (Hofstede, 1980). In essence masculine cultures focus on achievement and advancement, whereas feminine cultures highlight quality of life and good relationships (Hofstede, 1980). Individualism finally refers to the significance or importance placed on the individual (Hofstede, 1980). With individualistic cultures the focus is on individual goals and independence. On the other hand, with collectivistic cultures the focus is on group goals and interdependence (Triandis, 1995).

\subsection{Vietnamese Work Culture}

The Vietnamese work culture has been described by various authors as collectivistic and hierarchical, with higher levels of uncertainty avoidance (Zhu, 2003; Quang \& Vuong, 2002, Berrel, Wright, \& Hoa, 1999). Several studies have referred to the Vietnamese inclination towards the collective. For example, Kamoche (2001) observed that in Vietnam, employees are often expected to put employer's interests first. In turn the employers' are expected to take care of their employees like family. There will be a 'loss of face' if either parties fail to live up to expectations. This practice is a result of the strong Confucian influence on Vietnamese social life that commenced more than a thousand years ago. Nonetheless Zhu (2003) noted that this age old practice is being challenged in modern Vietnam today. Younger, more qualified employees are apparently more willing to abandon this paternalistic relationship to pursue greener pastures elsewhere.

A number of studies have also suggested the Vietnamese inclination towards power distance, albeit depending on context. Quang and Vuong (2002) study on state owned and privately owned companies in Vietnam, for example found the preferred management style to be familial and directive. The joint ventures on the other hand were more inclusive and participative. In a more recent study, Vo and Hannif (2013) observed the same. They noted that the local companies may be more autocratic and collective but the multinationals and the joint ventures were decidedly more participative. Contrary to expectations, the employees in these companies expressed much enthusiasm at being able to contribute to the organization. The younger employees especially appeared to expect autonomy and participation as given.

Other studies indicated the Vietnamese inclination for avoiding uncertainty. Berrell, Wright and Hoa (1999) observed that the Vietnamese employees exhibited behaviours that preclude uncertainties. This included a preference for job security and a clearly defined career path. Quang and Vuong (2002) similarly noted that the Vietnamese employees can often feel threatened by ambiguity. To avoid this rather uncomfortable situation, 
employers should always ensure job stability and formal rules. Nonetheless Tuan and Napier (2000) and Thang et al. (2007) opined that the Vietnamese reported aversion to uncertainty can be quite deceptive. They observed the Vietnamese employees' apparent willingness to take on risks when the situation demands it.

\section{Method}

The qualitative research method was employed in this study. The aim is to explore the managers' experience of communication at the international workplace. The purpose is to understand deeply the issues or concerns with workplace communication from the perspective of the foreign managers. As such semi-structured interviews were conducted on 19 foreign managers who had extensive experience working with the local Vietnamese employees.

The managers were selected from 7 organizations headquartered in the United States, England or Australia with subsidiaries or joint ventures in Vietnam. The organizations were all service based, providing essential financial and non-financial services such as auditing, banking, tax consultancy, education and training.

All the managers had more than two years' experience managing and working with the local employees. They ranged in age from 30 to 55 years. They were also recommended by the various trade groups, chambers of commerce and business acquaintances. Demographic details of the samples are included in appendix 1. To ensure privacy and confidentiality, the names of all participants were replaced with synonyms. Field work in HCMC took place between 2010 and 2011. After the initial pilot interviews, a set of interview questions was developed. Probing questions were used to help the participants relate their experiences including, what were the concerns the managers had with regards to communication? Why were they a concern? What did the managers think was the cause or reason for their concern? What did they do next? What did they want the employees do to encourage communication?

All the interviews were conducted by the researcher. Permission to tape record the interviews was obtained from most of the managers. Two of the managers however declined permission due to privacy concerns. As such only key words and ideas were jotted down. The interviews ranged in duration from an hour to an hour and a half each. Field notes were taken during and immediately after the interviews to record any insights gained and questions raised. Any queries were followed up with phone calls or emails to the respondents. The researcher transcribed more than half the recorded interviews. The rest of the transcripts were completed by a hired help. The researcher would however review the transcripts to make sure they were verbatim.

The interview transcripts were analysed using the grounded theory, constant comparative method described by Strauss and Corbin (1990). An iterative process of carefully reading the interview data and coding the emerging patterns was developed to generate the themes or categories associated with the participants perceptions of communication issues at work. To ensure accuracy and reliability the researcher also got a colleague to review and analyse a couple of the interview transcripts. Differences in opinions were discussed at length and reconciled. The themes or categories generated are described in the next section.

\section{Results}

\subsection{Communicating with the Vietnamese Employees: The Foreign Managers Views}

The foreign managers regularly mentioned the difficulty of finding the 'right' employees. They had no problems attracting candidates to apply for positions in the company. Nevertheless recruiting employees who fit their needs and requirements remained a challenge.

\subsection{Work Orientation}

One concern that the managers had was work independence. More specifically the managers wanted the employees to be able to plan and organize their own work. This includes the employees' completing assigned work, following up on issues and adhering to agreed timeline. For several of the managers their employees' disappointed in this respect. One manager remarked,

'I try not to tell them what to do. I let them think about what they have to do first. But what I realize after a while, things don't get done. Maybe they did not think that I was serious enough about it.'

The affected managers grumbled that they often had to give the employees specific instructions. The younger employees especially would do well with specific instructions but would falter when the managers neglected to do so. The managers also groused that they had to constantly remind the employees to follow up on issues or to warn them of impending deadlines. Discussions with the managers revealed their deep seated disdain for the reminders. The general feeling is they should not be telling or reminding the employees what to do all the time as they had other more urgent matters to attend to. 
Independent work also included the employees having a mind of their own. Several of the managers remarked that they had difficulties getting the employees to voice opinions or to express their feelings on a subject matter. One manager put it this way:

'I've been here 2 years now and I still cannot get people to speak up and when I ask them. They will say something, but I have to ask them for it.'

When pressed, the managers noted that their employees would often say what they thought the managers wanted them to say. Compounding the situation further, the employees would rarely question or challenge the managers. One manager noted that his employees would 'rather please the manager than displease them.' The employees' focus apparently is to facilitate close relation and avoid any disagreements.

In direct contrast the managers wanted the employees to be more 'critical' about work matters and not just do whatever the managers tell them. Having an opinion seemed most important. When an employee expressed their opinions or ideas, it not only demonstrates thinking but also interest in what they are doing at work. Conversely when an employee refrains from doing so they may be deemed as disinterested. One manager warns of the consequences of not speaking up and of not having an opinion, '... all of our staffs are opinionated, we train them to have their views and be firm with their views. After the first year, either they change and become more vocal or they will leave.'

\subsection{Work Communication}

The other concern that was discussed was work communication or rather the lack of it. Niggling frustrations were expressed over the lack of communication coming from their employees. The managers clamored for more communication including asking questions and giving feedback. The managers were especially concern with asking questions. The general feeling was asking question is most important but the employees were not doing enough of it. The following comment highlights the managers' sentiments,

'I'd rather the employees over - communicate than under-communicate. I'd rather they ask me the same question 10 times and get it right than once and make all kinds of mistakes.'

The managers implored the employees to ask questions, especially with regards to job instructions. The managers wanted the employees to question them if they are not clear on job instructions. Even when the employees are quite sure on what to do, the employees should still confirm with the managers to ensure the right 'direction' and best 'approach.' Most importantly, the employees should not assume they know what the managers want and make unnecessary mistakes.

The managers also appealed for more feedback from the employees. The managers highlighted two types of feedback, namely feedback on job progress and feedback on job issues. The managers were particularly concerned with feedback on job progress. They desired to be kept informed on the goings on of a job as much as possible. Revealingly, the managers noted that the feedback was less about keeping tabs on the employees than about helping the employees complete their jobs. Apparently the employees do not do enough of that leaving them fearing for the worst all the time. One manager remarked,

'They (the employees) need to talk more to the managers. There got to be more communication. We need to know what's happening in the job. What are they doing? Where are they? They don't talk about the things that we like to know enough.'

The managers also sought feedback on job issues. The managers wanted to be kept informed on issues and problems that may affect job quality and delivery. This included mistakes and oversights made by the employees. From the managers' perspective, feedback on job issues is most important to ensure that remedial steps be taken to address the issues as soon as possible. Several of the managers however observed the employees' reticence. One manager talked about his employees not wanting to bring 'bad news' for fear they would be blamed. Another manager remarked that his employees would be quite 'un-communicative ... especially if they like have done something wrong or they think that they have made a mistake.'

\subsection{Work Language}

Finally, concerns were expressed on the employees' language ability. Several of the managers indicated that they had few problems with language at work. Apparently, one of the major employee selection criteria for the managers interviewed is language proficiency. Recruitment wise, only employees with a high standard of English are ever considered for selection. Other managers however tended to differ. Questions were still raised on their employees' command of the language in terms of vocabulary and depth of understanding.

The employees' vocabulary or lack of it including jargon was a bane to some of the managers. Jargons are 
simply technical words specific to an industry. To succeed at work, employees are generally required to have a minimum knowledge of the jargon. The managers however observed that their employees often struggled with even basic jargon. Other managers were more concerned with depth of understanding. They talked about their employees having limited understanding of the many words used at work. The impression was the employees knew the words but they did not understand them or they understand them quite differently.

Importantly, the perceived deficit in vocabulary and understanding presented the managers with considerable challenges. Several of the managers pointed out that they had difficulty getting their employees to understand job instructions. They grumbled about the need to review job instruction over and over again. Other managers remarked that their employees' often struggled to analyse issues in work reports. Apparently the reports produced would lack depth of insight and be peppered with grammatical mistakes.

Accordingly the managers would have to spend an inordinate amount of time editing the report which they were not particularly keen on. Some of the managers found the language situation exasperating. They did not mind taking time off to explain job instructions or to edit reports. Nevertheless, the general feeling is this is not what they should be doing all the time. Going over the basics of language with the employees distracts the managers from other more urgent matters.

\section{Discussions}

The dominant theme coming from the interviews is the lack of communication. The managers were concerned with the lack of communication including feedback and questioning. The managers' concerns correspond with previous studies in Western individualistic culture. In an early study on work communication in the United States, DiSalvo, Larsen and Seilor (1976) found that managers desired their employees to be able to give feedback and engage in discussion. More recently, Hawkins and Fillion (1999) observed that for managers, effective communication includes use of clear language and questioning.

The focus on communication comes in part from the emphasis on work independence. Work independence or autonomy is a work practice that is favored by individualistic cultures (Erez, 2010). The belief is work independence would make for a more commited and motivated employee. Enabling the employees to take on responsibilities and be rewarded for it should spur the employees to work harder. The work practice however increases the requirement for communication. With work independence, feedback is most important as the managers' still needs to know what is going on. Autonomy also requires the the employees to come forward with questions when in doubt.

The managers' desire for communication nevertheless faces a number of challenges. Various writers observed the challenges of communication in collective cultures. Members of collective cultures such as the Vietnamese have been described as being anxious or apprehensive over talk (Gudykunst \& Ting Toomey, 1988). When they do talk, they are likely to be implicit and indirect (Hall, 1976), modest and passive (Lustig \& Koester, 2010) and obliging and avoiding (Trubisky et al., 1991), especially in difficult situations

One factor contributing to the reticence is hierarchical roles. Gudykunst and Ting Toomey (1988) noted that communication for collectivistic cultures tends to be contextual. That is, what and how they communicate depend very much on the situation including the status and roles of the communicators. In schools, the teachers instruct. The students, on the other hand defer to the teachers (Hwa-Froelich \& Westby, 2003). At work, the managers direct. The employees in turn do not challenge or disagree with their managers (Dickson, DenHartog \& Mitchelson, 2003). They prefer to be 'to be told what to do'(Hofstede, 2010, p. 73).

Closely linked to roles is consideration for others. When communicating, members of collective cultures are constraint by the issue of 'other face' (Ting \& Toomey, 1994). The idea is, it is most important to not offend or embarass important others when speaking. Any communication should be discrete or indirect to maintain good relations and harmony. In organizations, this concern for 'other face' would invariably prevent employees from giving feedback or giving suggestions (Aycan, 2004). Negative feedback or criticisms to more senior personnel would be especially avoided. Less than positive feedback should be avoided not only to prevent incidents of face loss but also to circumvent undesirable consequences.

There is also the inherent negative perception of talk. Lustig and Koester (2010) observed that unlike Western culture there is a general suspicion over talk in East Asia. The Taoist analogy of 'the one who talks does not know' and the Buddhist proverb of 'true communication only occurs when one speak without the mouth' (p. 236) only reflects the level of mistrust over verbal communication. Finally, there is the issue of competency and confidence. Ayres (1997) pointed out that a person would be highly apprehensive over communication if he feels he lacks the necessary competencies and would be assessed on them. There are requisite skills in giving 
feedback and asking questions. Any perceived lack would prevent the employees from engaging in them. In Vietnam, where the English language remains a distant second or third language, language and communication competencies remain a pertinent issue.

In sum getting the employees to communicate, particularly verbal communication remains a challenge in Vietnam due to hierarchical roles, face concerns and skills. As such proactive steps must be taken to facilitate communication at work.

\section{Recommendations for Practice}

Interviews with the managers plus insights drawn from the literature suggest a number of strategies to encourage communication and at the same time facilitate work independence and involvement. These are discussed next.

\subsection{Build relations}

you have to make a connection. I find that unless you make that connection, unless they see you immersing in their culture, it will be difficult for them to open up.'

Various writers in Vietnam recognized the imperative of close relations to communication (Thang et al., 2007; Borton, 2000). Close relations can be facilitated in part by showing interest in the employees. Showing interest in turn can be demonstrated by the managers inquiring their employees of their wellbeing and pitching in to help. This can be further augmented by the adoption of the open door policy. That is, employees should be able walk into the managers' office and share their concerns or difficulties without any feelings of fear or anxiety. Close relations can also be gained by the manager 'hanging' out with their employees at informal events such as the after office hours drinks and the occasional birthday parties or wedding dinners. Mingling with the employees at these events is most important as the managers' not only get to connect with their employees', but the managers' also get to better understand them.

\subsection{Build Empathy or Understanding}

Understanding the employees is vital to connecting with them deeply. Several of the managers mentioned the importance of listening and understanding 'where the employees are coming from.' This includes adapting their ways of doing things to that of the employees. Empathetic understanding and adaptation on the managers' part would in turn demonstrate respect and draw the employees to work more closely with them. In contrast, insisting on one's way of doing things is a sure way to disaffect and alienate the employees. Apparently the foreign managers don't do enough of that. Instead of listening to the employees and adapting, the managers would often insist that the employees follow them. One manager described it this way,

'I think a lot of foreigners don't do that. They have this colonial type of mentality. They are staffs, they don't have your experiences, your western education and all the things that you bring ... you're the expert, so they should do what you tell them to do'

\subsection{Set Expectations from the Start}

'With the new graduates, you must tell them exactly what you want at the beginning. If you do that they will be fine.'

Managers must ensure that the employees are aware of their expectations. What do the managers' want from the employee, including communication? New employees especially are often unsure what they are supposed to do. They are uncertain of what constitute appropriate behaviors, communication or otherwise. For example, what questions should be asked and how to ask them. Or, what type of feedback should be offered to management and when. On the managers' parts, carefully articulating their expectations at the outset would help the employees adjust to the demands placed on them at work faster.

\subsection{Plan for Communication Skills Training}

'Vietnamese staff should be trained with professional communication. Most of us, I mean most of us, the Vietnamese staff are not trained with that. We are just trained with English language.'

Effective communication requires skills such as the ability to explain, clarify, persuade, argue and question. These skills do not come naturally but need to be worked at gradually. New recruits particularly may lack the necessary skills. Nguyen and Robinson (2010) talked about the current education system that does not do enough to prepare the employees for the modern workplace. This lack of skills in turn may hold the employees back from interacting with the managers. Thus training the employee in the requisite skills is most important to make them more confident and more willing to communicate. 


\subsection{Provide for Individual Coaching and Mentoring}

Classroom training should be supplemented with individual coaching and mentoring. Classroom training is useful in dispensing knowledge information. Imparting intricate work skills gained from personal experiences however may require on the job coaching and mentoring. Coaching is particularly pertinent in Vietnam as it allows the managers to develop close relations with the employee and at the same time assist them in acquiring the skills necessary to succeed at work today. Proper guidance would ensure the employees not only survive but thrive in the new work environment.

\subsection{Consult the Employees}

'Communication does not just mean speaking, communication is also about listening. As a manager are you a good listener? Do you give time to your employees to speak?

Generally, to consult means to discuss with the employees. This includes querying them on their ideas and most importantly, listening to their suggestions. With the contextual, indirect communication there is greater emphasis on listening. The onus lies with the managers to listen to what the employees are really saying including making qualified inferences. According to Borton (2000) and Zhu (2003) consultation and consensus is most important to managing and making good decisions in Vietnam. Contrary to stereotypes managers in Vietnam do have to get the employees agreement to succeed.

\subsection{Schedule Regular One on One Consultation Sessions}

Managers should set aside regular time to consult the employees. The employees may not be comfortable with volunteering feedback or suggestions to their superiors, at least at the start. That is not standard practice in collective hierarchical cultures like Vietnam. Scheduling regular discussions, formal and informal may encourage the employees to do so. Further, the consultations or discussions should be private and confidential to safeguard employee sensitivities. A couple of the managers talked about providing the employees a 'safe place' where they can voice their ideas and opinions without fear of being ridiculed or reprimanded to encourage unhindered communication.

\subsection{Reduce Hierarchy or Power Distance}

'There is like the middle age men who are more likely to be a bit more straigh forward, they think of you as sort of equal. With 20 year Vietnamese women, you have to draw an answer out of her.'

In Vietnam, differences in power and status can adversely affect communication. As such, managers should take steps to reduce the differential. The question is how? One way hierarchy can be allayed is by developing close relations. Close relations does not only improve relations but it also reduces hierarchy (Thang et al., 2007). Aycan (2004) talked about the manager being both a boss and a friend to the employee. The ability of the manager to manage the dual role is central to successful interaction with the employees.

Hierarchy can also be reduced by not micromanaging the employees. Managers should avoid any inclination to direct and monitor what the employees do all the time. One manager talked about 'sharing' rather than 'lecturing' when giving employees direction to get their 'buy in'. Another manager talked about, 'showing' the employees what to do rather than telling them what to do to encourage cooperation. Additionally managers should avoid disparaging the employees harshly for mistakes made. Instead more effort should be made to show the employees where they went wrong and how they can improve. The focus should be on fixing the problem rather finding someone to blame.

Finally hierarchy can be reduced by the use of technology. Differential powers are less pronounced in emails and instant messages as there are fewer formalities or protocols to be concerned with. Younger employees' especially, who are more familiar with the medium would find it less intimidating to speak up to higher authorities. Additionally, emails provide the employees' a tool to better express themselves. Face to face communication often put the employees in a spot to explain or to clarify their ideas quickly. Emails in contrast allow the employees' the luxury of time to look up the dictionary and find suitable words to construct sentences that would better convey their ideas. As result, employees who are less articulate and less expressive would be more willing and more confident to communicate.

\section{Conclusion}

This study revealed the challenges foreign managers in Vietnam face in getting the employees to communicate including giving feedback and asking questions. The disinclination or the inability to communicate up to their managers' remains a key concern as reflected in a number of studies conducted locally (World Bank, 2012). The results of this study are not unexpected as various literature mentioned communication as a key issue in 
traditional collective cultures.

Nguyen and Robinson (2010) and World Bank (2013) however all talked about Vietnam being a country that is undergoing rapid change. On the one hand the economy is slowly but surely transforming from a centrally planned to an open, market economy. On the other, the economy is depending more on manufacturing and services for growth than its previous mainstay, agriculture. This turn of events requires corresponding changes in labor requirements. There is a greater demand today for workers that have the skills set that matches the manufacturing and service sector than the agricultural sector.

To survive in the workplace, employees have to adapt to the new work environment by acquiring new more relevant skills including communication. This adjustment should be considerably hastened by the employees' industry. Interviews with the managers all point to the employees' tremendous willingness to learn and to work hard to achieve success.

One manager described the dynamism of the Vietnamese employees this way, 'There is a popular saying that the Vietnamese work, the Cambodian watch, and the Laotian sleep. I think it's an excellent characterization of these three Indochinese countries. The people here are so energetic and dynamic'. Nonetheless the manager can assist the employees along with the adjustment process. Correspondingly this study made several recommendations to managers to encourage more communication at work including building close relations at work and building informal structures in the organization to facilitate communication.

Finally, this exploratory study suggests several areas for further investigation. For a start, it would be invaluable to study the employees' experience of communication at work and what do they think are the issues at work. They would have different perspectives on matters due to their very different backgrounds and training. More studies should also be conducted on upward communication or the lack of it in the Vietnam context. A constant theme from this study is the employees' reticence in communicating up to their managers. There has been an increasing interest in the subject matter in the US recently (Milliken, Morrison, \& Hewlin, 2003) due in part to its perceived less than positive effects on organizational performance. Similar studies should be made to study the extent of the effects on organizations in Asia.

\section{References}

Aycan, Z. (2004). Leadership and teamwork in the developing country context. The Blackwell handbook of global management: A guide to managing complexity (pp. 406-422). Malden, MA: Blackwell Publishing.

Ayres, J. (1997). A component theory of communication apprehension. Ruston, WA: Communication Ventures.

Berrell, M., Wright, P., \& Van Hoa, T. T. (1999). The influence of culture on managerial behavior. Journal of Management Development, 18(7), 578-589. http://dx.doi.org/10.1108/02621719910284431

Borton, L. (2000). Working in a Vietnamese voice. The Academy of Management Executive, 14(4), 20-29. http://dx.doi.org/10.5465/AME.2000.3979813

Dickson, M. W., Den Hartog, D. N., \& Mitchelson, J. K. (2003). Research on leadership in a cross-cultural context: Making progress, and raising new questions. The Leadership Quarterly, 14(6), 729-768. http://dx.doi.org/10.1016/j.leaqua.2003.09.002

DiSalvo, V., Larsen, D. C., \& Seiler, W. J. (1976). Communication skills needed by persons in business organizations. Communication Education, 25(4), 269-275. http://dx.doi.org/10.1080/03634527609384640

Duoc, T. Q., \& Metzger, C. (2007). Quality of business graduates in Vietnamese institutions: Multiple perspectives. Journal of Management Development, 26(7), 629-643. http://dx.doi.org/10.1108/02621710710761261

EIU. (2013). Country Report: Vietnam. London: Economic Intelligence Unit.

Erez, M. (2010). Culture and job design. Journal of Organizational Behavior, 31(2), 389-400. http://dx.doi.org/10.1002/job.651

Gudykunst, W. B., \& Ting-Toomey, S. (1988). Culture and affective communication. American Behavioral Scientist, 31(3), 384-400. http://psycnet.apa.org/doi/10.1177/000276488031003009

Hall, E. T. (1976). Beyond culture. New York: Doubleday.

Hawkins, K. W., \& Fillion, B. P. (1999). Perceived communication skill needs for work groups. Communication Research Reports, 16(2), 167-174. http://dx.doi.org/10.1080/08824099909388714

Hofstede, G. H. (1980). Culture's consequences. Beverly Hills, Ca: Sage Publications. 
Hofstede, G. H. (2001). Culture's Consequences: Comparing Values, Behaviors, Institutions and Organizations Across Nations. Beverly Hills, CA: Sage Publications.

Hwa-Froelich, D. A., \& Westby, C. E. (2003). A Vietnamese Head Start Interpreter: A Case Study. Communication Disorder Quarterly, 24(2), 86-98. http://dx.doi.org/10.1177/15257401030240020501

Kamoche, K. (2001). Human resources in Vietnam: The global challenge. Thunderbird International Business Review, 43(5), 625-650. http://dx.doi.org/10.1002/tie.1019

Kluckhohn, F. R., \& Strodtbeck, F. L. (1961). Variations in value orientations. Greenwood Press.

Lustig, M., \& Koester, J. (2010). Intercultural competence: Interpersonal communication across cultures. Boston, MA: Pearson Prentice Hall.

Montague, A. (2013). Vocational and skill shortages in Vietnamese manufacturing and service sectors, and some plausible solutions. Asia Pacific Journal of Human Resources, 51(2), 208-227. http://dx.doi.org/10.1111/j.1744-7941.2012.00060.x

Milliken, F. J., Morrison, E. W., \& Hewlin, P. F. (2003). An Exploratory Study of Employee Silence: Issues that Employees Don't Communicate Upward and Why. Journal of Management Studies, 40(6), 1453-1476. http://dx.doi.org/10.1111/1467-6486.00387

Nguyen, P. A., \& Robinson, A. G. (2010). Managing continuous improvement in Vietnam: Unique challenges and approaches to overcome them. Quality Management Journal, 17(2)

Quang, T., \& Vuong, N. T. (2002). Management styles and organisational effectiveness in Vietnam. Research and Practice in Human Resource Management, 10(2), 36-55. Retrieved from http://rphrm.curtin.edu.au/2002/issue2/vietnam.html

Rowley, C., \& Truong, Q. (2009). The changing face of Vietnamese management. London: Routledge.

Samovar, L. A., Porter, R. E., \& McDaniel, E. R. (2009). Communication Between Cultures. Boston, MA: Cengage Learning.

Scott, P., \& Bannon, W. (2008). Managing for Success in Vietnam. HCMC, Vn: Nhà xuất bản Trẻ.

Strauss, A., \& Corbin, J. (1990). Basics of qualitative research: Grounded theory procedures and techniques. Newbury Park, CA: Sage Publications.

Thang, L. C., Rowley, C., Quang, T., \& Warner, M. (2007). To what extent can management practices be transferred between countries? The case of human resource management in Vietnam. Journal of World business, 42(1), 113-127. http://dx.doi.org/10.1016/j.jwb.2006.11.005

Ting-Toomey, S. (1994). The challenge of facework: Cross-cultural and interpersonal issues. New York: Suny Press.

Triandis, H. C. (1995). Individualism \& collectivism. Boulder, CO: Westview Press.

Trubisky, P., Ting-Toomey, S., \& Lin, S. L. (1991). The influence of individualism-collectivism and self-monitoring on conflict styles. International Journal of Intercultural Relations, 15(1), 65-84. http://dx.doi.org/10.1016/0147-1767(91)90074-Q

Trung, T. Q., \& Swierczek, F. W. (2009). Skills development in higher education in Vietnam. Asia Pacific Business Review, 15(4), 565-586. http://dx.doi.org/10.1080/13602380802364175

Tuan, V. V., \& Napier, N. K. (2000). Paradoxes in Vietnam and America: lessons learned. Human Resource Planning, 23(1), 7-8. http://www.highbeam.com/doc/1G1-65354209.html

Vo, A., \& Hannif, Z. N. (2013). The reception of Anglo leadership styles in a transforming society: The case of American companies in Vietnam. The International Journal of Human Resource Management, 24(18), 3534-3551. http://dx.doi.org/10.1080/09585192.2011.616526

World Bank. (2012). Putting Higher Education to Work: Skills and Research for Growth in East Asia. Washington, DC: World Bank.

World Bank. (2013). Skilling up Vietnam: Preparing the workforce for a modern market economy. Washington, DC: World Bank.

Zhu, Y. (2003). Culture and management in Vietnam. Culture and Management in Asia. London: Routledge. 


\section{Appendix 1. Managers demographic}

\begin{tabular}{|c|c|c|c|c|c|}
\hline Code & Organization type & $\begin{array}{ll}\text { Years in } \\
\text { Vietnam }\end{array}$ & Gender & Age Range & Nationality \\
\hline FM1 & Consulting & 5 & M & 3140 & American \\
\hline FM2 & Banking & 3 & M & $31-40$ & Canadian \\
\hline FM3 & Accounting & 4 & $\mathrm{~F}$ & $31-40$ & Australian \\
\hline FM4 & Banking & 2 & M & $41-50$ & Philippines \\
\hline FM5 & Accounting & 5 & $\mathrm{~F}$ & $21-30$ & Malaysian \\
\hline FM6 & Banking & 7 & $\mathrm{~F}$ & $51-60$ & Singaporean \\
\hline FM7 & Consulting & 2 & M & $41-50$ & American \\
\hline FM8 & Advertising & 4 & M & $31-50$ & Philippines \\
\hline FM9 & Banking & 2 & M & $41-50$ & Philippines \\
\hline FM10 & Accounting & 3 & $\mathrm{~F}$ & $31-40$ & Malaysia \\
\hline FM11 & Consulting & 8 & M & $31-40$ & New Zealand \\
\hline FM12 & Accounting & 3 & $\mathrm{~F}$ & $31-40$ & India \\
\hline FM13 & Banking & 2 & $\mathrm{~F}$ & $21-30$ & Vietnamese \\
\hline FM14 & Advertising & 5 & $\mathrm{~F}$ & $31-40$ & Philippines \\
\hline FM15 & Banking & 3 & $\mathrm{~F}$ & $31-40$ & Thailand \\
\hline FM16 & Banking & 3 & $\mathrm{~F}$ & $31-40$ & Thailand \\
\hline FM17 & Consulting & 4 & $\mathrm{~F}$ & $31-40$ & Malaysian \\
\hline FM18 & Accounting & 5 & M & $31-40$ & Malaysian \\
\hline FM19 & Accounting & 5 & $\mathrm{M}$ & $31-40$ & Malaysian \\
\hline
\end{tabular}

\section{Copyrights}

Copyright for this article is retained by the author(s), with first publication rights granted to the journal.

This is an open-access article distributed under the terms and conditions of the Creative Commons Attribution license (http://creativecommons.org/licenses/by/3.0/). 